\title{
Guest driven structural transformation studies of a luminescent metal-organic framework
}

\author{
BIPLAB MANNA, SHWETA SINGH and SUJIT K GHOSH* \\ Indian Institute of Science Education and Research (IISER), Dr. Homi Bhabha Road, Pune, \\ Maharashtra 411008 , India \\ e-mail: sghosh@iiserpune.ac.in
}

MS received 10 April 2014; revised 26 May 2014; accepted 6 June 2014

\begin{abstract}
A two-dimensional (2D) porous metal-organic framework (MOF) $\left[\left\{\mathrm{Zn}_{2}(\mathrm{~L})_{4}(\mathrm{OTf})_{4}\right\} \cdot 2(\mathrm{DCM}) . x \mathrm{G}\right]_{\mathrm{n}}$ (1)G) (OTf = trifluoro methane sulfonate, DCM = Dichloromethane, L (1, 4-bis (4-pyridyl)-2, 3-diaza-1, 3butadiene) synthesized at room temperature. Free guests DCM were encapsulated in the pores of the MOF. On air drying the MOF loses free DCM molecules and changed its structure in a crystal to crystal manner to produce compound $1\left[\left\{\mathrm{Zn}(\mathrm{L})_{2}(\mathrm{OTf})_{2}\right\} . \mathrm{XG}\right]_{\mathrm{n}}(\mathbf{1})$. This guest-induced breathing of the framework was also supported from PXRD patterns. Solid state photoluminescence properties of the dynamic MOF were studied at room temperature.
\end{abstract}

Keywords. Metal-organic frameworks; coordination polymers; dynamic framework; crystal to crystal transformation; luminescence.

\section{Introduction}

Metal-Organic frameworks (MOFs) or porous coordination polymers have drawn immense attention not only due its aesthetic architectures but also due to its wide range of potential applications in the field of gas storage, chemical separation, drug delivery, catalysis, optics, sensing. ${ }^{1-6}$ In the recent past, flexibility in MOFs has been found to be of great interest due to its unique guest-responsive function and enhanced hostguest interactions over the rigid porous frameworks. ${ }^{7}$ Dynamic MOFs are very sensitive to external/chemical stimuli and they change their structure upon variation of guest molecules inside its frameworks. ${ }^{8}$ Such guest dependent dynamic structural property of the flexible PCPs makes them potential candidates for the smart sensors and gas separating materials. ${ }^{9}{ }^{10}$ Dynamic behaviours of this kind of materials are often understood from their single crystal to single crystal (SCSC) transformation studies. ${ }^{11}$ It is not always easy to get a single crystal after removal of a guest from the parent framework. Sometimes this guest removal process occurs so fast that a very weak crystalline phase or amorphous phase gets generated.

*For correspondence
Combinations of flexible $4,4^{\prime}-\mathrm{N}$ donor functionality of a ligand with metal salt in low boiling solvent system at room temperature often render MOFs which generally encapsulate low boiling solvents as free guests in the pores. These MOFs generally exhibit flexible character because they often lose those trapped guests upon air drying of the MOFs crystals and undergo structural variations, often termed as guest induced breathing phenomena. ${ }^{12}$ Luminescence can be incorporated into the dynamic framework by making use of $\mathrm{d}^{10}$ metal ions with the complexation of a neutral flexible $4,4^{\prime} \mathrm{N}$ donor ligand. ${ }^{13}$ Keeping all the above points in mind, a smart material with bimodal functionality (dynamic and luminescent) can be developed. Here we strategically choose flexible ligand $\mathrm{L}^{14}$ (1, 4-bis (4-pyridyl)-2, 3-diaza-1, 3butadiene) and $\mathrm{Zn}$ (II) metal ion in low boiling solvent system to generate a dynamic luminescent MOF.

Herein, we present a $2 \mathrm{D}$ porous metal-organic framework $\left[\left\{\mathrm{Zn}_{2}(\mathrm{~L})_{4}(\mathrm{OTf})_{4}\right\} .2(\mathrm{DCM}) . \mathrm{x}(\mathrm{G})\right]_{\mathrm{n}}(\mathrm{G}$ are disordered guest molecules)(1) built from $\mathrm{Zn}$ (II) and ligand $\mathbf{L}$ synthesized at room temperature. The compound exhibits guest dependent structural dynamism. This guest dependent structural dynamism of the MOF has been well demonstrated by single crystal to single transformation (SCSC) and powder X-ray diffraction (PXRD) studies. Solid state photoluminescence of the air dried phase of the compound is measured at room temperature. 


\section{Experimental}

\subsection{Materials}

All the reagents were commercially available and used as supplied without further purification. Ligand $\mathbf{L}$ was synthesized according to the reported protocol. ${ }^{14} \mathrm{Zn}$ (II) triflate was purchased from Aldrich Chemical. Co. All the other solvents used were purchased locally.

\subsection{Synthesis of Compound $1 \supset G\left[\left\{Z_{2}(L)_{4}(O T f)_{4}\right\}\right.$.} $\left.2(D C M) \cdot x(G)_{2}\right]_{n}(\mathbf{1} \supset \boldsymbol{G})$

DCM solution of the ligand $(21.023 \mathrm{mg}, 1 \mathrm{~mL})$ was taken into a glass tube, onto that 1-propanol $(1 \mathrm{~mL})$ was carefully layered and over the 1-propanol layer, solution of $\mathrm{Zn}(\mathrm{OTf})_{2}$ (36.353 mg, $1 \mathrm{~mL}$ ) in $\mathrm{MeOH}$ was very carefully layered. Block shaped yellow crystals suitable for $\mathrm{X}$-ray studies were obtained after 15 days in $70 \%$ yield.

\subsection{Synthesis of Compound $1\left[\left\{\operatorname{Zn}(L)_{2}(\text { OTf })_{2}\right\} . x G\right]_{n}$ (1)}

When the crystals of parent compound $1 \supset \mathrm{G}$ were taken out from its mother liquor and kept for air drying for about half an hour, it changed to yellow coloured compound $\mathbf{1}$.

\section{$2.4 \quad X$-ray crystallography}

Single-crystal X-ray data of $\mathbf{1} \supset \mathbf{G}$ and $\mathbf{1}$ were collected at $100 \mathrm{~K}$ on a Bruker KAPPA APEX II CCD Duodiffractometer (operated at $1500 \mathrm{~W}$ power: $50 \mathrm{kV}$, $30 \mathrm{~mA}$ ) using graphite-monochromated Mo $\mathrm{K} \alpha$ radiation $(\lambda=0.71073 \AA)$. The crystal was on nylon CryoLoops (Hampton Research) with Paraton-N (Hampton Research). The data integration and reduction were processed with SAINT ${ }^{15}$ software. A multi-scan absorption correction was applied to the collected reflections. The structure was solved by the direct method using SHELXTL ${ }^{16}$ and was refined on $\mathrm{F}^{2}$ by full matrix least-squares technique using the SHELXL-97 ${ }^{17}$ program package within the WINGX ${ }^{18}$ program. All non-hydrogen atoms were refined anisotropically. All hydrogen atoms were located in successive difference Fourier maps, and they were treated as riding atoms using SHELXL default parameters. PLATON ${ }^{19}$ squeeze programme was used for the structures to remove diffuse electron density associated with badly disordered solvent molecules (tables 1 and 2).

Table 1. Crystal data and structure refinement for Compound $1 \supset \mathrm{G}$.

\begin{tabular}{ll}
\hline Identification code & Compound $1 \supset \mathrm{G}$ \\
Empirical formula & $\mathrm{C}_{55} \mathrm{H}_{45} \mathrm{Cl}_{4} \mathrm{~F}_{12} \mathrm{~N}_{15} \mathrm{O}_{12} \mathrm{~S}_{4} \mathrm{Zn}_{2}$ \\
Formula weight & 1736.84 \\
Temperature & $100(2) \mathrm{K}$ \\
Wavelength & $0.71073 \AA$ \\
Crystal system & Monoclinic \\
Space group & $\mathrm{Cc}$ \\
Unit cell dimensions & $\mathrm{a}=19.8102(15) \AA$ \\
& $\mathrm{b}=24.4012(19) \AA$ \\
& $\mathrm{c}=18.1151(14) \AA$ \\
Volume & $7704.3(10) \AA^{3}$ \\
$Z$ & 4 \\
Density (calculated) & $1.497 \mathrm{Mg} / \mathrm{m}^{3}$ \\
Absorption coefficient & $0.962 \mathrm{~mm}^{-1}$ \\
F (000) & 3504 \\
Crystal size & $0.11 \times 0.17 \times 0.21 \mathrm{~mm}^{3}$ \\
Theta range for data collection & 1.51 to $25.00^{\circ}$. \\
Index ranges & $-20<=\mathrm{h}<=23,-28<=\mathrm{k}<=28,-21<=1<=21$ \\
Reflections collected & 54434 \\
Independent reflections & $10862[\mathrm{R}(\mathrm{int})=0.0231]$ \\
Completeness to theta $=25.00^{\circ}$ & $99.9 \%$ \\
Refinement method & Full-matrix least-squares on $\mathrm{F}^{2}$ \\
Data/restraints/parameters & $10862 / 656 / 937$ \\
Goodness-of-fit on $\mathrm{F}^{2}$ & 2.931 \\
Final R indices [I 2 sigma(I)] & $\mathrm{R} 1=0.1383, \mathrm{wR} 2=0.3292$ \\
R indices (all data) & $\mathrm{R} 1=0.1446, \mathrm{wR} 2=0.3375$ \\
Absolute structure parameter & $0.28(2)$ \\
\hline &
\end{tabular}


Table 2. Crystal data and structure refinement for Compound 1.

\begin{tabular}{|c|c|c|}
\hline Identification code & Compound 1 & \\
\hline Empirical formula & $\mathrm{C}_{26} \mathrm{H}_{20} \mathrm{~F}_{6} \mathrm{~N}_{8} \mathrm{O}_{6} \mathrm{~S}_{2} \mathrm{Zn}$ & \\
\hline Formula weight & 783.99 & \\
\hline Temperature & $100(2) \mathrm{K}$ & \\
\hline Wavelength & $0.71073 \AA$ & \\
\hline Crystal system & Orthorhombic & \\
\hline Space group & $\mathrm{I} 222$ & \\
\hline \multirow[t]{3}{*}{ Unit cell dimensions } & $\mathrm{a}=9.0511(11) \AA$ & $\alpha=90^{\circ}$ \\
\hline & $b=17.789(3) \AA$ & $\beta=90^{\circ}$ \\
\hline & $\mathrm{c}=24.112(3) \AA$ & $\gamma=90^{\circ}$ \\
\hline Volume & $3882.3(9) \AA^{3}$ & \\
\hline $\mathrm{Z}$ & 4 & \\
\hline Density (calculated) & $1.341 \mathrm{Mg} / \mathrm{m}^{3}$ & \\
\hline Absorption coefficient & $0.814 \mathrm{~mm}^{-1}$ & \\
\hline $\mathrm{F}(000)$ & 1584 & \\
\hline Theta range for data collection & 1.42 to $28.29^{\circ}$ & \\
\hline Index ranges & $-12<=\mathrm{h}<=12,-23<=\mathrm{k}<=23,-32<=1<=30$ & \\
\hline Reflections collected & 34931 & \\
\hline Independent reflections & $4828[\mathrm{R}($ int $)=0.0329]$ & \\
\hline Completeness to theta $=28.29^{\circ}$ & $99.9 \%$ & \\
\hline Refinement method & Full-matrix least-squares on $\mathrm{F}^{2}$ & \\
\hline Data/restraints/parameters & $4828 / 37 / 222$ & \\
\hline Goodness-of-fit on $\mathrm{F}^{2}$ & 2.739 & \\
\hline Final $R$ indices $[\mathrm{I}>2 \operatorname{sigma}(\mathrm{I})]$ & $\mathrm{R} 1=0.1047, \mathrm{wR} 2=0.3083$ & \\
\hline $\mathrm{R}$ indices (all data) & $\mathrm{R} 1=0.1077, \mathrm{wR} 2=0.3109$ & \\
\hline Absolute structure parameter & $0.49(4)$ & \\
\hline
\end{tabular}

\subsection{Physical measurements}

FT-IR spectra were measured on a Nicolet 6700 FTIR spectrophotometer by making $\mathrm{KBr}$ pellets (400$4000 \mathrm{~cm}^{-1}$ ). X-ray powder patterns were recorded on a BrukerD8 advanced X-ray diffractometer using $\mathrm{Cu}$ $\mathrm{K} \alpha$ radiation $(\lambda=1.5406 \AA)$ with scan rate 0.4 s/step and step size $0.01^{\circ}$, and thermogravimetric analyses were recorded with heating rate of $10^{\circ} \mathrm{C} / \mathrm{min}$ under $\mathrm{N}_{2}$ atmosphere on a Perkin-Elmer STA 6000 TGA analyzer. Solid state UV were recorded on Perkin Elmer Lamda 900 UV/ VIS Spectrometer. The solid-state fluorescence spectra were recorded on Fluorolog 3.

\section{Results and Discussion}

Combination of ligand $\mathrm{L}$ and $\mathrm{Zn}$ (II) triflate in a solvent system of DCM/1-propanol/ $\mathrm{MeOH}$ at room temperature yielded yellow coloured block-shaped crystals of $\left[\left\{\mathrm{Zn}_{2}(\mathrm{~L})_{4}(\mathrm{OTf})_{4}\right\} \cdot 2(\mathrm{DCM}) \cdot \mathrm{xG}\right]_{\mathrm{n}}(\mathbf{1} \supset \mathbf{G})$. The Single crystal X-ray analysis (SC-XRD) of compound 1つG revealed that compound crystallized in monoclinic crystal system with space group $C c$. An asymmetric unit of the compound contains two $\mathrm{Zn}$ (II), four ligands (L), four $\mathrm{CF}_{3} \mathrm{SO}_{3}^{-}$(triflate) anions, two dichloromethane (DCM) molecules as guests and disordered guests. Coordination of four Nitrogens of different ligands and two oxygens of two different trilate anions makes each metal ion octahedral environment. Each ligand ligates to a metal centre through its nitrogen atom at the terminal position and at the same time another terminal nitrogen of the same ligand binds to another metal centre. Thus, extension of these co-ordinations formed 2D planar sheets along $\mathrm{c}$ axis. Careful analysis of the structure of $\mathbf{1} \supset \mathbf{G}$ reveals that chlorine atom of DCM molecule and coordinated oxygen of $\mathrm{CF}_{3} \mathrm{SO}_{3}^{-}$undergo weak chemical interactions with central nitrogen of the long flexible ligand and 4 pyridyl nitrogen respectively. Overall 3D packing of $1 \supset \mathbf{G}$ shows that the presence of 1D channels along c axis, which encapsulate free DCM molecules (figure 1). A noteworthy feature of the compound is its dynamic structural behaviour. When compound $\mathbf{1}$ JG was taken out form its mother liquor and kept outside for air drying for about half an hour, it showed a drastic structural change to a new phase (Compound 1) without losing its single crystalline nature. Single crystal analysis of compound 1 showed large differences in unit cell parameters with loss of free DCM molecules as 


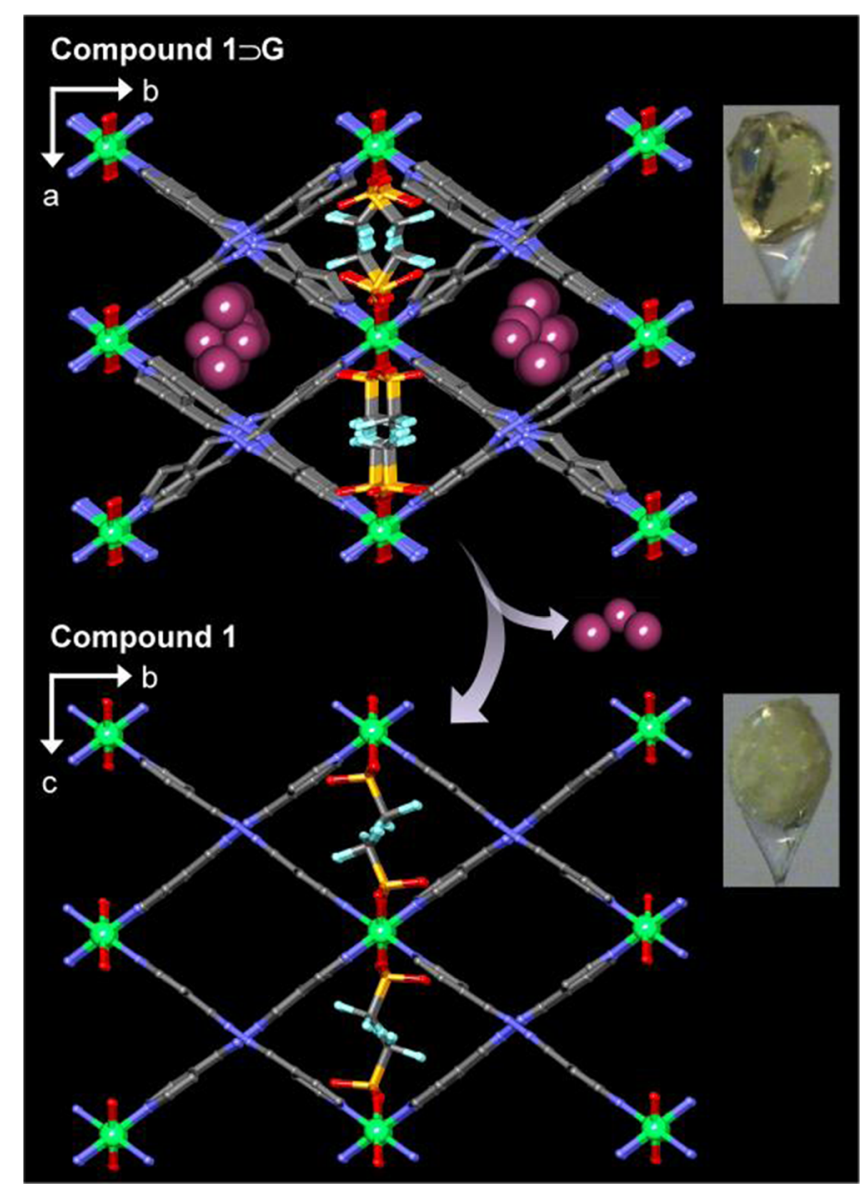

Figure 1. Guest induced dynamic structural transformation from compound $\mathbf{1} \mathbf{D} \mathbf{G}$ to $\mathbf{1}$ in a SCSC manner with the corresponding single crystal images.

guests as illustrated by $\mathbf{1}\left[\left\{\mathrm{Zn}(\mathrm{L})_{2}(\mathrm{OTf})_{2} \cdot \mathrm{xG}\right]_{\mathrm{n}}\right.$. Complete SCSC structural analysis revealed that the crystal system of compound $\mathbf{1}$ changed to orthorhombic with a change in space group from $\mathrm{Cc}$ to I222. The metal centre is in octahedral geometry and coordination environment remains almost unchanged. Bond lengths and bond angles around $\mathrm{Zn}$ (II) centre are very similar. The overall 3D packing of $\mathbf{1}$ also shows that formation of $1 \mathrm{D}$ channels along a axis (figure 1). Very close examination of both the structures revealed that the contraction of M-M-M angle of a single 2D net on departure of free guests.

During the structural transformation M-M-M angle of a single 2D net changed from $102.80^{\circ}$ (1) $\mathbf{G}$ ) to $100.77^{\circ}$ (1) (figure 2) accompanied by a change in shape and size of $1 \mathrm{D}$ porous channels. This leads to the breathing of the framework from $8.772 \AA$ (1)G) to $9.984 \AA$ (1) considering M-M distances along the porous channels (figure 3 ).

Compound $\mathbf{1}$ is stable in its single crystalline form, but it changes its structure in powder form as evident

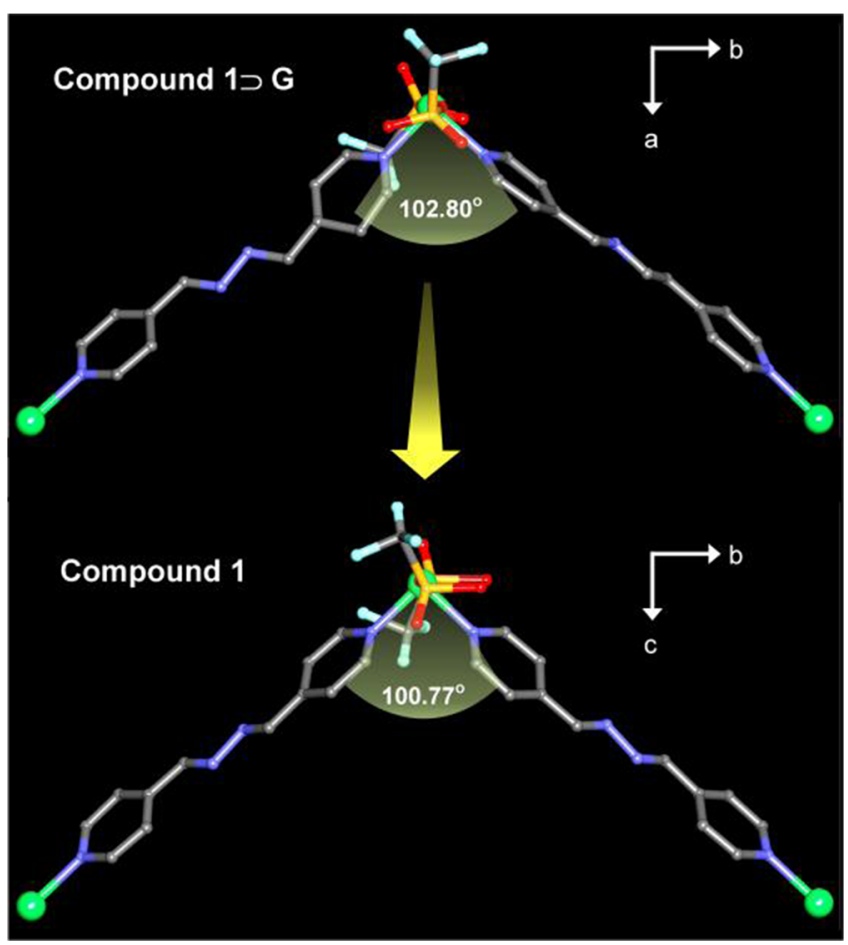

Figure 2. M-M-M angle (of a single 2D net) changes during the structural transformation.

from slight variation in powder X-ray diffraction (PXRD) patterns of compound $\mathbf{1}$ at different time intervals (figure 4). Hence we designate the bulk powder of compound $\mathbf{1}$ as $\mathbf{1}$ '.

The thermo gravimetric analysis (TGA) of compound $\mathbf{1}^{\prime}$ in $\mathrm{N}_{2}$ atmosphere revealed an approximate $\sim 6 \%$ wt loss at temperature $133^{\circ} \mathrm{C}$ and the compound is further stable up to $240^{\circ} \mathrm{C}$ (figure 5) .

FT-IR spectral analysis of the compound 1' indicates the strong band observed at $\sim 1300 \mathrm{~cm}^{-1}$ which corresponds to presence of $\mathrm{CF}_{3} \mathrm{SO}_{3}{ }^{-}$in the framework (figure 6).

Solid state UV was measured for free ligand and compound 1' in its air dried condition. The spectra showed minimum reflectance at wavelength $\sim 370 \mathrm{~nm}$ for both free ligand and air dried compound (figure 7).

Solid state emission spectra were recorded for free ligand and compound 1' at room temperature. Upon excitation at $370 \mathrm{~nm}$, ligand $\mathrm{L}$ displays three emission bands at $407 \mathrm{~nm}, 428 \mathrm{~nm}$ and $563 \mathrm{~nm}$ respectively. Among the three bands, the band at $428 \mathrm{~nm}$ is the most intense one. Compound 1' showed an intense band at $558 \mathrm{~nm}$ with a weak band at $431 \mathrm{~nm}$ and a shoulder at $409 \mathrm{~nm} \cdot{ }^{20,21} \pi *-\mathrm{n}$ and $\pi *-\pi$ intraligand transitions are mainly responsible for these emissions (figure 8). 


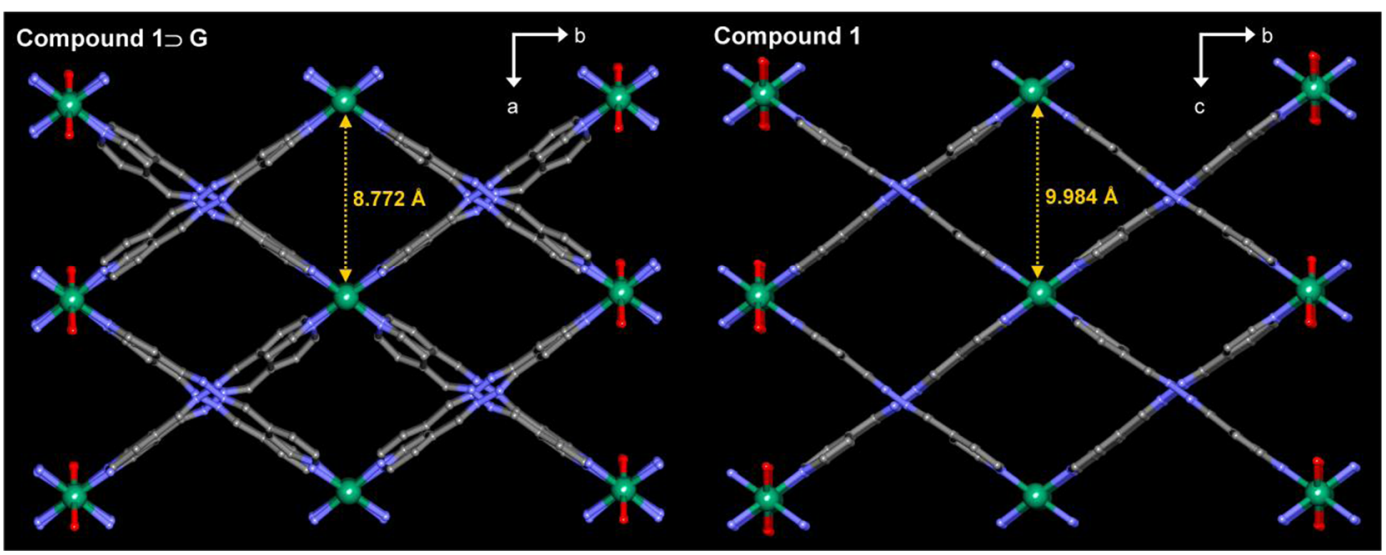

Figure 3. Guest induced breathing of the framework during structural transformation.
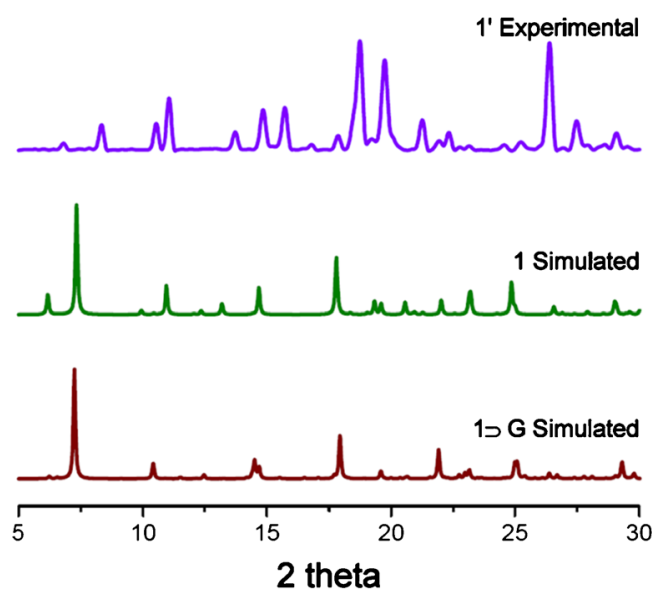

Figure 4. Powder X-ray diffraction (PXRD) patterns of compound 1.

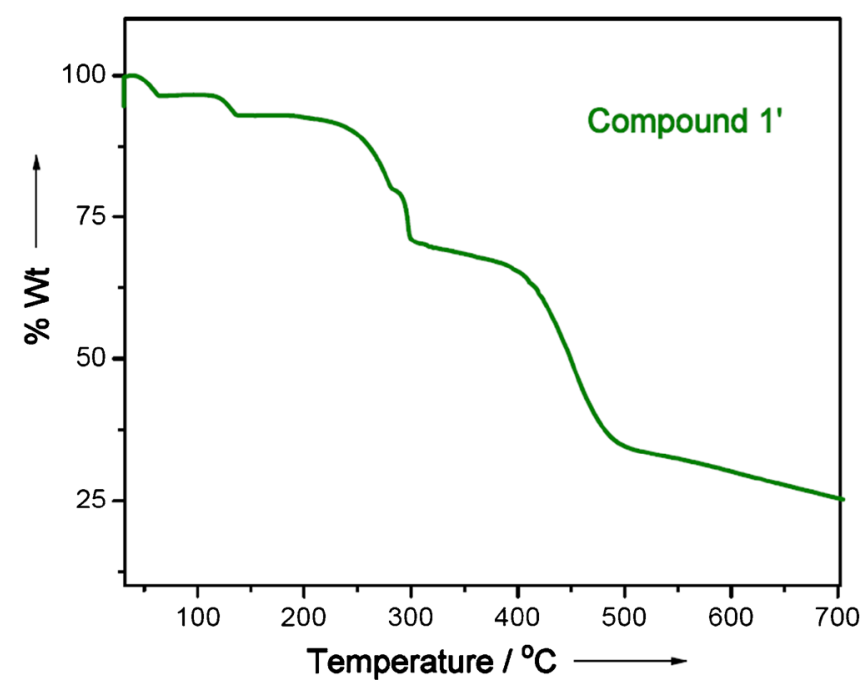

Figure 5. Thermogravimetric analysis of Compound 1'.

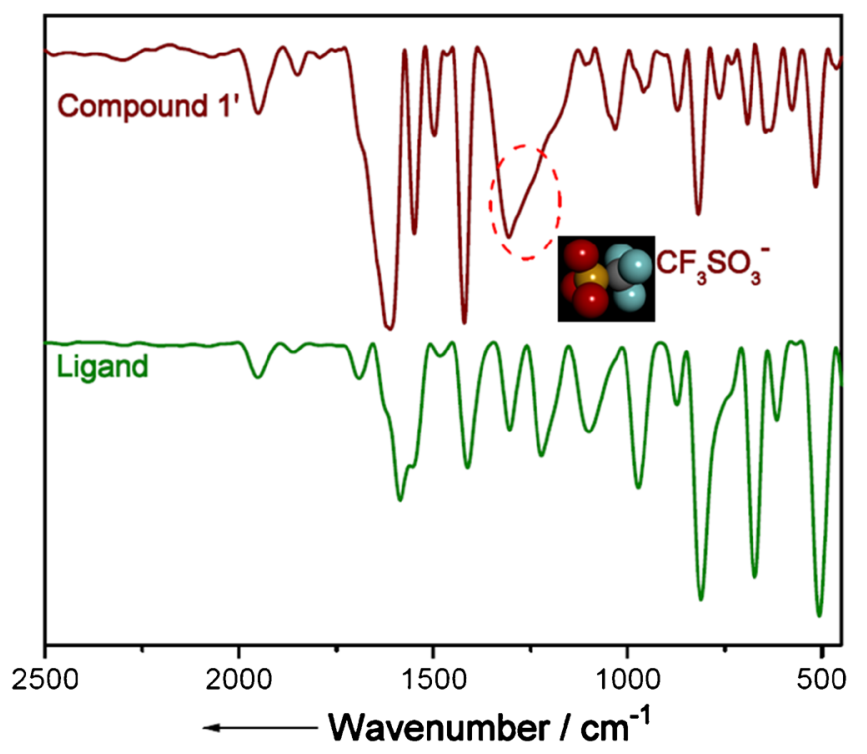

Figure 6. FT-IR spectra of free ligand and Compound 1'.

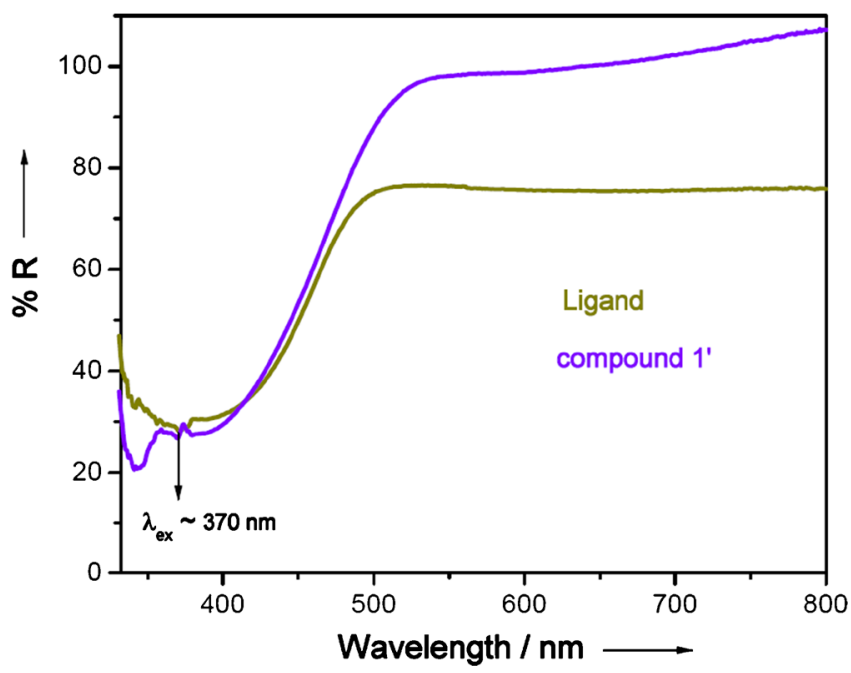

Figure 7. Solid-state UV spectra of free ligand and compound $\mathbf{1}$ ' at room temperature. 


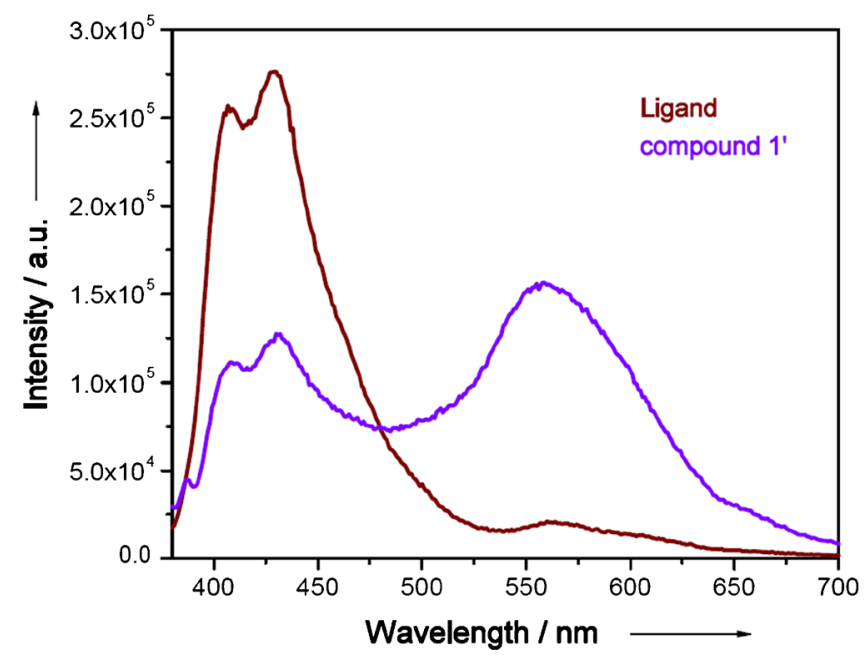

Figure 8. Solid state photoluminescence spectra of free ligand and compound 1' at room temperature.

\section{Conclusion}

We have synthesized a 2D porous dynamic luminescent metal organic framework. The compound showed guest induced breathing of the framework. The guest dependent structural dynamism has been well demonstrated by SCSC experiments and PXRD patterns of the compounds. Solid state UV and photoluminescence were studied for the compound at room temperature. This structurally dynamic behaviour along with luminescence property of the compound might be very useful as a guest-responsive material for efficient separation purpose.

\section{Supplementary Information}

Crystallographic data for the structural analysis have been deposited with the Cambridge Crystallographic data Centre. CCDC 996229 (1) $\mathbf{G})$ and CCDC 996228 (1). Copies of the data can be obtained free of charge at www.ccdc.cam.ac.uk/conts/retrieving.html [or from the Cambridge Crystallographic Data Centre, 12 Union Road, Cambridge CB21EZ, UK, Fax: (internet) +441223-336-033; E-mail: deposit@ccdc.cam.ac.uk.

\section{Acknowledgements}

$\mathrm{BM}$ is thankful to the Council of Scientific \& Industrial Research (CSIR) for research fellowship. We are grateful to IISER Pune for research facilities and the Department of Science and Technology (DST) (Project no. GAP/ DST/CHE-12-0083) and The Department of Atomic Energy (DAE) (Project no. 2011/20/37C/06/BRNS) for financial support.

\section{References}

1. Eddaoudi M, Kim J, Rosi N, Vodak D, Wachter J, O'Keeffe M and Yaghi O M 2002 Science. 295469

2. Li J-R, Kuppler R J and Zhou H-C 2009 Chem. Soc. Rev. 381477

3. An J, Geib S J and Rosi N L 2009 J. Am. Chem. Soc. 1318376

4. Lee J Y, Farha O K, Roberts J, Scheidt K A, Nguyen S T and Hupp J T 2009 Chem. Soc. Rev. 381450

5. Guo Z, Cao R, Wang X, Li H, Yuan W, Wang G, Wu H and Li J 2009 J. Am. Chem. Soc. 1316894

6. Chen B, Xiang S and Qian G 2010Acc. Chem. Res. 431115

7. Horike S, Shimomura S and Kitagawa S 2009 Nat. Chem. 1695

8. Ghosh S K, Bureekaew S and S Kitagawa 2008 Angew. Chem. Int. Ed. 473403

9. Uemura K, Kitagawa S, Fukui K and Saito K 2004 J. Am. Chem. Soc. 1263817

10. Yanai N, Kitayama K, Hijikata Y, Sato H, Matsuda R, Kubota Y, Takata M, Mizuno M, Uemura T and Kitagawa S 2011 Nat. Mater. 10787

11. Manna B, Chaudhari A K, Joarder B, Karmakar A and Ghosh S K 2013 Angew. Chem. Int. Ed. 52998

12. Biradha K and Fujita M 2002 Angew. Chem. Int. Ed. 41 3392

13. Chen Y-Q, Li G-R, Chang Z, Qu Y-K, Zhang Y-H and Bu X-H 2013 Chem. Sci. 43678

14. Ciurtin D M, Dong Y-B, Smith M D, Barclay T, Loye H-C Z 2001 Inorg. Chem. 402825.

15. SAINTPlus (Version 7.03); BrukerAXS Inc.: Madison, WI 2004

16. Sheldrick G MSHELXTL, Reference Manual, Version 5.1; BrukerAXS: Madison, WI, 1997

17. Sheldrick G M Acta Crystallogr. Sect. A 2008112

18. Farrugia, L J WINGX version 1.80.05; University of Glasgow: Glasgow, 2009

19. Spek A L, PLATON, A Multipurpose Crystallographic Tool; Utrecht University: Utrecht, The Netherlands, 2005

20. Zhang G, Yang G and Ma Jin Shi 2006 Cryst. Growth. Des. 61897

21. Vyasamudri S Y and Maji T K 2009 Chem. Phys. Lett. 473312 